\title{
Health Management for Medical-surgical Female Nurses Having Night Shift Working
}

\author{
Kazuo Minematsu ${ }^{1,2^{*}}$, Tae Yamaguchi ${ }^{3}$, Mitsuyo Nakashima ${ }^{4}$, Noriaki Tsunawake ${ }^{5}$ and Narumi Ooshige ${ }^{6}$ \\ ${ }^{1}$ Department of School Health, Graduate School of Education, Nagasaki University, Nagasaki, Japan \\ ${ }^{2}$ Department of Public Health, Juntendo University, Tokyo, Japan \\ ${ }^{3}$ Department of Nursing, University of Nagasaki, Nagasaki, Japan \\ ${ }^{4}$ School of Nursing, Faculty of Medicine, Fukuoka University, Fukuoka, Japan \\ ${ }^{5}$ Graduate School of Human Health Science, University of Nagasaki, Nagasaki, Japan \\ ${ }^{6}$ Department of Growth and Development Nursing, Japanese Red Cross Kyusyu International College of Nursing, Fukuoka, Japan
}

\section{Abstract}

Background: Female nurses are highly susceptive to night shift work. Age, nap times during night shift, physical activity level, and lifestyles strongly associated with fatigue at night shift; however, a comprehensive analysis of these factors including psychological research could not be conducted.

Purpose: The purpose of this study is to prove the risk factors for fatigue of medical-surgical female nurses having night shift working based on the data of demographics, lifestyles, subjective symptoms, and performance status from pre night shift to post-holiday.

Methods: This cross-sectional study was conducted on 97 Japanese female night shift nurses. The data of age, body mass index, clinical experience years, lifestyles, and nap time during night shift were collected. Total steps, energy expenditure, and subjective symptoms; drowsiness, instability, uneasiness, dullness, and eye strain had been continuously measured and evaluated from pre night shift to post-holiday. Nurses who recovered from fatigue were assigned to a recovery group; other nurses were assigned to a non-recovery group based on improvements in total five subjective symptoms between pre night shift and post-holiday.

Results: Age, body mass index, nap time length during night shift, clinical experience years, performance status, and lifestyles were not different between recovery group and non-recovery group. Logistic regression analysis showed that drowsiness and eyestrain are significant risk factor for fatigue at night shift. Adjusted odds ratio ( $95 \%$ confidence interval) for fatigue in medical-surgical female nurse having night shift were $2.04(1.36-3.01)$ in drowsiness and $2.03(1.30-3.18)$ in eyestrain $(\mathrm{P}<0.001)$.

Conclusions: Psychological detachment from work environment is important for recovering fatigue from night work-stressors during night shift. Nursing management should be positively organized for protecting medical-surgical female nurses' health having night shift and for preventing medical error.

\section{Background}

Shift work disturbs the natural circadian rhythms, and nurses suffer from an unfavorable condition known as shift lag and desynchrony [1]. Factors influencing fatigue of nurses have been studied extensively and work-related factors, psychological factors, and demographic factors have been recognized as contributing to nurse fatigue $[2,3,4]$. It is important for night shift workers not to perturb biological rhythms. Sleepiness and fatigue among shift workers are known as potential risks for occupational safety and health in many industries [5]. Taking a nap during the night shift has been suggested as an effective way to prevent fatigue or other complaints related to shift work[6]. Nursing is a profession that typically involves shift work as nurses are required to provide continuous health care for the patients [7].

Especially, female nurses having family has extra burden of home responsibilities and sleep changes strongly affects menstrual cycle $[8,9]$. Night shift with attention-demanding has been acknowledged as a serious risk factor for female nurse's health [10]. Physical, emotional, and social stress are exposed by sleep disturbances in shift-work [7]. Female nurses are affected by environmental factors, including family commitments and work strain, which can cause difficulty falling sleep, frequent awaking, and premature awakening [11].

Recently, life style after night shift for recovering from work-induced fatigue has been brought to attention [12]. Exercise or social behavior chronic fatigue [7]. 4978/2017/216 original author and source are credited.

\section{Publication History:}

Received: December 17, 2016

Accepted: January 09, 2017

Published: January 11, 2017

\section{Keywords:}

Night shift working, Medicalsurgical female nurses, Fatigue, Risk factor, Psychological detachment, Nap time, Eyestrain, Drowsiness to decrease work-related complications. Active and fulfilling nonwork-time behaviors are more significant in maximizing recovery from work strain than is commonly recognized. High mental and emotional strain has been shown to recover better through active exercise, to levels over and above the simple rest afforded by being removed from the stressful work environment [13]. Regular exercise can lead to a healthy lifestyle, reduce stress, and reduce feelings of

However, there has been no comprehensive study for improving that tried to prove the interrelationship among occupational factors, life-related factors including family environment of nurses with night shift. We hypothesized that age, clinical experience years as nurse, and clinical experience years of night shift including the above-mentioned

"Corresponding Author: Dr. Kazuo Minematsu, Department of School Health, Graduate School of Education, Nagasaki University, Nagasaki, Japan, Tel: +8195-819-2359; E-mail: minematsu@nagasaki-u.ac.jp

Citation: Minematsu K, Yamaguchi T, Nakashima M, Tsunawake N, Ooshige N (2017) Health Management for Medical-surgical Female Nurses Having Night Shift Working. Int J Nurs Clin Pract 4: 216. doi: https://doi.org/10.15344/2394-

Copyright: @ 2017 Minematsu et al. This is an open-access article distributed under the terms of the Creative Commons Attribution License, which permits unrestricted use, distribution, and reproduction in any medium, provided the 
Citation: Minematsu K, Yamaguchi T, Nakashima M, Tsunawake N, Ooshige N (2016) Health Management for Medical-surgical Female Nurses Having Night Shift Working. Int J Nurs Clin Pract 4: 216. doi: https://doi.org/10.15344/2394-4978/2017/216

factors may associate with the accumulation of fatigue at night shift and the recovery from fatigue. Also, nurses with higher physical activity level after night shift (at holiday) may effectively recover from fatigue after night shift. Therefore, this study would contribute to improve fatigue at night shift in medical-surgical female nurses.

\section{Materials and Method}

\section{Participants}

97 Japanese medical-surgical female nurses were recruited from two regional private hospitals in Nagasaki prefecture, Japan. We divided the subjects into two groups; recovery group and non-recovery group based on improvements in fatigue feelings (total points of drowsiness, instability, uneasiness, dullness, and eyestrain) between pre night shift and post-holiday. Recovery group was defined by the minus point from post-holiday to pre night shift. If the value was zero, this subject was defined as recovery group.

\section{Instruments}

The demographics data (age, body mass index (BMI), clinical experience years as nurse, clinical experience years of night shift, and daily life styles) and occupational data (nap time length and steps during night shift) in medical-surgical female nurses were collected by questionnaire. Drowsiness, instability, uneasiness, dullness, and eyestrain as the subjective fatigue symptoms from pre night shift to post holiday were evaluated. These subjective fatigue symptoms were assessed by a questionnaire that asked about work-related feelings of fatigue Jikaku-sho sirabe, which was proposed by the Industrial Fatigue Research Committee of Japanese Occupational Health [14]. Physical activity levels (steps and energy expenditure (EE)) from pre night shift to post holiday were examined by three dimensions speed sensor. Physical activity levels were measured by Actimaker (EW4800, Panasonic, Japan).

\section{Data collection}

Data collection took place from April 2012 to February 2013. All nurses were recruited from two private hospitals in Nagasaki, Japan. The subjective symptoms were evaluated at four points; pre- and post-night shift, and pre- and post- holiday using JSL recommended questionnaire. Responses for each component range from 0 to 5, with higher scores signifying poorer condition [14]. Recovery occurs when an individual's functioning returns to its pre-stressor level and when strain caused by the stressor is reduced [15]. Thus, the criteria of measurement point of fatigue in this study were from pre night shift to post holiday.

\section{Ethical considerations}

This project was reviewed and approved by the ethics committee of the University of Nagasaki. In addition, the purpose procedure of this study was explained to director of each hospital. Informed consent was obtained from all nurses.

\section{Data analysis}

Chi-square test and Mantel-Haenszel test for trend were conducted to examine the association between fatigue feelings and the demographics data. Differences of five fatigue symptoms at four measurement points between recovery group and non-recovery group were using Mann-Whitney test. The change of five subjective symptoms at four measurements points were confirmed by Friedman's test. Logistic regression analysis was utilized to prove the factors of fatigue at night shift nurses. Models were adjusted for clinical experience years as nurse, BMI, breakfast consumption habit, smoking habit, daily physical exercise habit, living with family, nap time length, variations of drowsiness, instability, uneasiness, dullness, and eyestrain from pre night shift to post holiday. Goodness of fit test was confirmed by Hosmer-Lemeshow. The variance inflation factor (VIF) is used as an indicator of multicollinearity. Probability values less than 0.05 were considered indicative of statistical significance. All statistical analyses were performed using SPSS ver 19.0 software (SPSS Japan, Tokyo, Japan). All data were expressed as median based on Kolmogorov-Sminov test.

\section{Results}

\section{Participant demographics}

Among the 97 shift-working female nurses participants, 39.2\% $(\mathrm{n}=38)$ were $20-29$ years old, $34.0 \%(\mathrm{n}=33)$ were $30-39$ years old, $14.4 \%(\mathrm{n}=14)$ were $40-49$ years old,9.3\% $(\mathrm{n}=9)$ were $50-59$ years old, and $3.1 \%(\mathrm{n}=3)$ were more than 60 years old. Median age was 31.6 years old (range: 21.6-61.3). Median clinical experience years as nurse was9.0 years. Mean clinical experience years of night shift was 9.0 years. The majority $(72.2 \%, n=70)$ had family. $8.2 \%(n=8)$ has smoking habit and $19.6 \%(\mathrm{n}=19)$ has regularly exercise habit more than two times per week. $66.0 \%(n=64)$ has breakfast consumption habit. All participant demographic data between recover group and non-recovery group were not significantly different using Chi-square test and Mantel-Haenszel test for trend (Table 1).

\section{Physical activity data from pre-night shift to post-holiday}

Table 1also shows physical activity data at the hospital and at home in recovery group and non-recovery group. In the total of 97 nurses, median BMI was $21.2 \mathrm{~kg} / \mathrm{m} 2$. The range of BMI was from 17.1 to $32.9 \mathrm{~kg} / \mathrm{m} 2.9 .3 \%(\mathrm{n}=9)$ was BMI $>25$. In the total of 97 nurses, median total steps and EE were 14363steps and 1958 kcalat night shift. At holiday after night shift, median total steps and EE were 3467 steps and $864 \mathrm{kcal}$. Total steps and EE were significantly different between at night shift and at holiday $(\mathrm{P}<0.001)$. Median nap time length during night shift was 75 minutes.

\section{The variations of five subjective symptoms from pre night shift to post-holiday}

Drowsiness, instability, uneasiness, dullness, and eyestrain from pre night shift to post night shift were not significantly different between recovery group and non-recovery group excluding eyestrain at postnight shift. Five subjective symptoms from pre-holiday to postholiday in non-recovery group were statistically higher than those in non-recovery group $(\mathrm{P}<0.05)$ (Table 2$)$. Five subjective symptoms were significantly different at four measurement points in both groups $(\mathrm{P}<0.001)$.

\section{Odds ratio for fatigue factors in Japanese night shift female nurses}

Factors that influence the recovery from night shift fatigue in Japanese female nurses were clarified by logistic regression analysis. Logistic regression models using step-wise were used to adjust for clinical experience years of night shift, BMI, breakfast consumption, smoking habit, daily physical exercise habit, living with family, nap time length, total steps at night shift, total steps at holiday, the 
Citation: Minematsu K, Yamaguchi T, Nakashima M, Tsunawake N, Ooshige N (2016) Health Management for Medical-surgical Female Nurses Having Night Shift Working. Int J Nurs Clin Pract 4: 216. doi: https://doi.org/10.15344/2394-4978/2017/216

Page 3 of 5

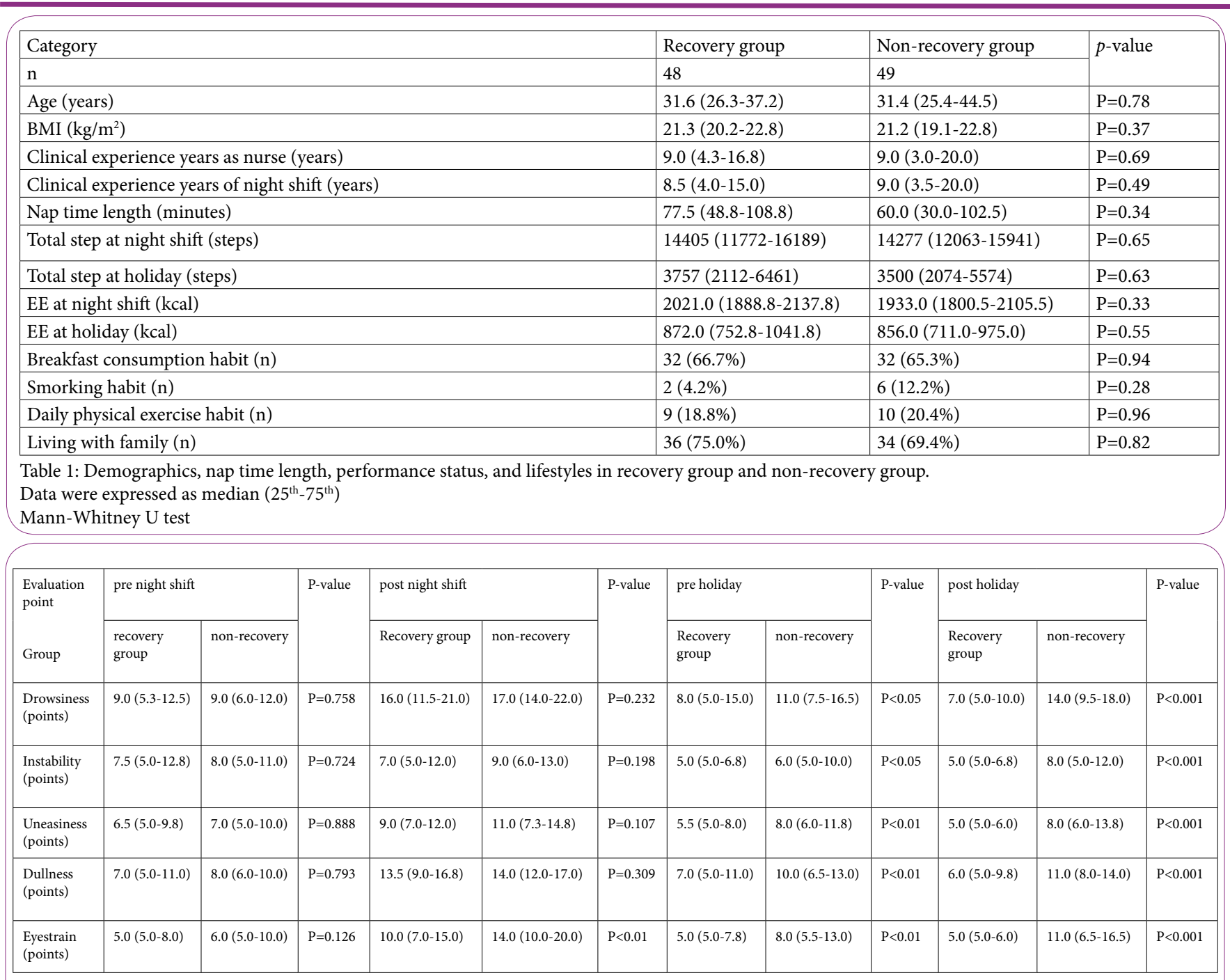

Table 2: Changes and differences of five fatigue symptoms in recovery group and non-recovery group from pre night shift to post-holiday.

Mann-Whitney U test

Data were expressed as median $\left(25^{\text {th }}-75^{\text {th }}\right)$

\begin{tabular}{|l|l|l|l|}
\hline Variables & Odds ratio & $95 \% \mathrm{CI}$ & $\mathrm{P}$-values \\
\hline Drowsiness & 2.04 & $1.36-3.01$ & $\mathrm{P}<0.001$ \\
\hline Eyestrain & 2.03 & $1.30-3.18$ & $\mathrm{P}<0.001$ \\
\hline
\end{tabular}

Table 3: Adjusted odds ratios (and 95\%CI) for fatigue in night shift working Japanese female nurses.

Note: Adjusted for clinical experience years as nurse, BMI, breakfast consumption, smorking habit, daily physical exxercise habit, living with family, nap time length, total step at night shift, total steps at holiday, variations of drowsiness, instability, uneasiness, dullness, and eyestrain from pre night shift to post holiday

Hosmer and Lemeshow: $\mathrm{P}=0.609, \mathrm{P}<0.001$

variation of drowsiness, instability, uneasiness, dullness, and eyestrain from pre-night shift to post holiday. The correlations among age, clinical experience years as nurse, and clinical experience years of night shift were quietly high $(\mathrm{R}>0.8)$; we thus cannot jointly analyze these variables at logistic regression models. Adjusted odds ratio (95\% confidence interval) for fatigue in medical-surgical female night shift nurses were 2.04(1.36-3.01) in drowsiness and 2.03(1.30-3.18) in eyestrain $(\mathrm{P}<0.001)$ (Table 3$)$.

\section{Discussion}

Work-related fatigue and recovery from fatigue are associated with age [16]. Fatigue from night shift can be effectively treated by aggressive life style as sports activity at day off [17]. Sports and related activities have positive effect on individual health and well-being [18]. However, people spend relatively little time on exercise and sport [19]. In this study, total steps and EE at holiday actually decreased compared to at night shift both recovery group and non-recovery group. Age, clinical experience years as nurse, and clinical experience years of night shift were not different between recovery group and non-recovery group. Also, physical activity level between two groups also did not differ. We suggested that these results have been shown to function as psychological detachment. Psychological detachment from work environment is recognized as important factor that helps to recover from job-stressors [20]. Our data clearly showed that drowsiness, instability, uneasiness, dullness, and eyestrain at post night shift were quietly high; however, these five subjective symptoms stupidly decreased at post night shift in both groups. These changes of subjective symptoms may reflect psychological relief from high work demands and high work stress at night shift. The exposure to 
Citation: Minematsu K, Yamaguchi T, Nakashima M, Tsunawake N, Ooshige N (2016) Health Management for Medical-surgical Female Nurses Having Night Shift Working. Int J Nurs Clin Pract 4: 216. doi: https://doi.org/10.15344/2394-4978/2017/216

Page 4 of 5

workplace related stressors is a predictor of cardiovascular diseases and higher systolic blood pressure, and psychological detachment from work environment of nurse who engaged in night shift contributes to recover from subjective symptoms [21].

Our research indicated that drowsiness and eyestrain were significantly risk factor for fatigue at night shift in female nurses. Drowsiness was 2.04 folds higher risk for recovering from night time shift's fatigue compared to recovery group. Eyestrain was 2.03 folds increased risk for recovering from fatigue at night shift. Recently, eyestrain has been brought to public attention. Eyestrain as well as sleep deprivation, especially in night shift nurses, is related to fatigue under the factors including mental-psychological state, occupational and social factors, and environmental factors [22].Preventing sleep deprivation among health care provider could be an extremely means of reducing medical errors and sleeping during night shift could be viewed as a strategy towards the reduction of errors [23]. Sleep deprivation, compounded by the circadian rhythms, is a profound health problem for nurse [21]. Fatigue is a critical problem for nurses that it leads to medication error, degradation in performance, personal health problem, job dissatisfaction, and frequent requests to quit from night shift [24]. Sleeping for 2-3 hours during night shifts is related to a better recovery from fatigue at night shift [25]. Taking a nap is an effective tool for improving working conditions during night shift [5]

In Japan, aging has been stupidly proceeding in the world. The burden, the quantity, and the quality of nursing care in Japanese nurses, especially medical-surgical female nurses, have been increasing. Untrained Japanese young nurses who are short clinical experience of night shift cannot avoid engaging in two-shift rotation system with nap. Nursing care and health services have to be offered on twentyfour hour basis. Nursing, with long work hours, is both physically and mentally demanding, which may lead to acute and fatigue [4] Thus, we need to positively manage work environment formedicalsurgical female nurses. Work-related factors, such as job demands, job control, support at work including support from supervisor and co-workers, physical work environments, and shift work were confirmed to contribute to fatigue in nurses[26]. Fatigue and recovery problems from fatigue strongly associated with partnership among nurses[24].Younger nurses in particular, need more support than is currently recognized if they are to be retained within the profession [16]. Psychological contributors like mood disorders (anxiety and depression) and sleep quality were also found to predict fatigue[27]. An important point to emphasize is that nursing managers should not only take consideration of psychological fatigue such as dullness and eyestrain in relation to nap during night shift but also pay attention to recovery process considered psychological detachment form stressful work environment when designing program to decrease female nurses'fatigue at night shift.

\section{Conclusions}

Our results suggest that psychological detachment for medicalsurgical female nurses form work environment is recognized as important factor that helps to recover from subjective symptoms. Moreover, the fact that drowsiness and eyestrain are the risk factor for fatigue at night time suggests the important of nursing management at hospital. Taking a rest with a nap, job control, partnership among nurses, and support at work, especially in younger nurse and untrained nurse, is the key issue when discussing nursing management in night shift female nurses, preventing medical error, and protecting nurses' health.

\section{Competing Interests}

The authors have no conflicts of interest to declare.

\section{Author contributions}

Kazuo Minematsu, Tae Yamaguchi, Mitsuyo Nakashima, Noriaki Tsunawake, and Narumi Ooshige were responsible for the study conception and design, and made critical revisions to the paper for important intellectual content. Tae Yamaguchi performed the data collection. Kazuo Minematsu, Mitsuyo Nakashima, Noriaki Tsunawake, and Narumi Ooshige were responsible for the drafting of the manuscript and for providing statistical expertise. Narumi Ooshige obtained funding and supervised the study.

\section{Acknowledgments}

We would like to thank all the participants, staff, and investigators who volunteered and were not financially compensated for their contributions to this study.

\section{Funding}

This research was supported by Kimura foundation for nursing education.

\section{References}

1. Berger AM, Hobbs BB (2006) Impact of shift work on the health and safety of nurses and patients. Clin J Oncol Nurs 10: 465-471.

2. Fang J, Kunaviktikul W, Olson K, Chontawan R, Kaewthummanukul T (2008) Factors influencing fatigue in Chinese nurses. Nurs Health Sci 10: 291-299.

3. Scott LD, Hofmeister N, Rogness N, Rogers AE (2010) Implementing a fatigue countermeasures program for nurses: a focus group analysis. $J$ Nurs Adm 40: 233-240.

4. Barker LM, Nussbaum MA (2011) Fatigue, performance and the work environment: a survey of registered nurses. J Adv Nurs 67: 1370-1382.

5. Takeyama H, Matsumoto S, Murata K, Ebara T, Kubo T, et al. (2004) Effects of the length and timing of nighttime naps on task performance and physiological function. Rev Saude Publica 38 Suppl: 32-37.

6. Matsumoto K (1981) Effects of nighttime naps on body temperature changes, sleep patterns, and self-evaluation of sleep. J Hum Ergol (Tokyo) 10: 173-184.

7. Shao MF, Chou YC, Yeh MY, Tzeng WC (2010) Sleep quality and quality of life in female shift-working nurses. J Adv Nurs 66: 1565-1572.

8. Gjerdingen D, McGovern P, Bekker M, Lundberg U, Willemsen T (2000) Women's work roles and their impact on health, well-being, and career: comparisons between the United States, Sweden, and The Netherlands. Women Health 31: 1-20.

9. Baker FC, Driver HS (2007) Circadian rhythms, sleep, and the menstrual cycle. Sleep Med 8: 613-622.

10. Ooshige N, Yamaguchi T, Nakashima M, Minematsu K, Tsunawake N (2012) Changes in physical activity and the feeling of fatigue after day and night duties. J Kyusyu Soc Rural Med 21:11-16.

11. Shaver JL (2002) Women and sleep. Nurs Clin North Am 37: 707-718

12. Kubo T, Takahashi M, Sallinen M, Kubo Y, Suzumura H (2013) How are leisure activity and shiftwork schedule associated with recovery from fatigue in shiftwork nurses? Sangyo Eiseigaku Zasshi 55: 90-102.

13. Winwood PC, Bakker AB, Winefield AH (2007) An investigation of the role of non-work-time behavior in buffering the effects of work strain. $\mathrm{J}$ Occup Environ Med 49: 862-871.

14. Kubo T, Takahashi M, Sato T, Sasaki T, Oka t, et al. (2011) Weekend sleep intervention for workers with habitually short sleep periods. Scand J Work Environ Health 37: 418-426. 
Citation: Minematsu K, Yamaguchi T, Nakashima M, Tsunawake N, Ooshige N (2016) Health Management for Medical-surgical Female Nurses Having Night Shift Working. Int J Nurs Clin Pract 4: 216. doi: https://doi.org/10.15344/2394-4978/2017/216

15. Craig A, Cooper RE. (1992) Symptoms of acute and chronic fatigue. In A P. Smith \& D. M. Jones (Eds.), Handbook of human performance London: Academic Press. Vol.3, 289-339.

16. Winwood PC, Winefield AH, Lushington K (2006) Work-related fatigue and recovery: the contribution of age, domestic responsibilities and shiftwork. $J$ Adv Nurs 56: 438-449.

17. Sonnentag $S$, Jelden $S$ (2009) Job stressors and the pursuit of sport activities: a day-level perspective. J Occup Health Psychol 14: 165-181.

18. Puetz TW, O'Connor PJ, Dishman RK. (2006) Effects of chronic exercise on feelings of energy and fatigue: a quantitative synthesis. Psychol Bull 132: 866-876.

19. Dubbert PM (2002) Physical activity and exercise: recent advances and current challenges. J Consult Clin Psychol 70: 526-536.

20. Sonnentag S, Binnewies C, Mojza EJ (2010) Staying well and engaged when demands are high: the role of psychological detachment. J Appl Psychol 95: 965-976.

21. van Amelsvoort LG, Kant IJ, Bültmann U, Swaen GM (2003) Need for recovery after work and the subsequent risk of cardiovascular disease in a working population. Occup Environ Med 60 Suppl 1: i83-87.

22. Azmoon H, Dehghan H, Akbari J, Souri S (2013) The relationship between thermal comfort and light intensity with sleep quality and eye tiredness in shift work nurses. J Environ Public Health 2013: 639184.

23. Landrigan CP, Czeisler CA, Barger LK, Ayas NT, Rothschild JM, et al. (2007) Effective implementation of work-hour limits and systemic improvements. Jt Comm J Qual Patient Saf 33: 19-29.

24. Jansen NW, van Amelsvoort LG, Kristensen TS, van den Brandt PA, Kant IJ (2003) Work schedules and fatigue: a prospective cohort study. Occup Environ Med 60 Suppl 1: i47-53.

25. Silva-Costa A, Rotenberg L, Griep RH, Fischer FM. (2011) Relationship between sleeping on the night shift and recovery from work among nursing workers-the influence of domestic work. J Adv Nurs 67: 972-981.

26. Yuan SC, Chou MC, Chen CJ, Lin YJ, Chen MC, et al. (2011) Influences of shift work on fatigue among nurses. J Nurs Manag 19: 339-345.

27. Kunert K, King ML, Kolkhorst FW (2007) Fatigue and sleep quality in nurses. J Psychosoc Nurs Ment Health Serv 45: 30-37. 